\title{
Analysis of Lithium Iron Phosphate Battery Damage
}

\author{
Yinquan $\mathrm{Hu}^{*}$, Xiaobing $\mathrm{Wu}$, Guorui Hu and Qiheng Fan \\ Chongqing Vocational Institute of Engineering, Chongqing, China
}

\begin{abstract}
Charge-discharge experiments of lithium iron phosphate $\left(\mathrm{LiFePO}_{4}\right)$ battery packs have been performed on an experimental platform, and electrochemical properties and damage mechanism of $\mathrm{LiFePO}_{4}$ batteries are also analyzed in extreme cases. Our results indicate that overcharge has little impact on utilizable capacity of the battery in the short term. Over-discharge has a huge impact on utilizable capacity of the battery. Based on these results, a management method of battery pack for reducing battery damage is proposed. At the same time, this method can also slow the rate of battery pack capacity attenuation and extend cycle life of battery pack.
\end{abstract}

\section{Introduction}

$\mathrm{LiFePO}_{4}$ batteries are widely used in various hybrid electric vehicles (HEV) and pure electric vehicles (EV) because of their many advantages, such as long cycle life, high theoretical capacity, environmental protection and other unmatched advantages [1-5]. The research shows that cycle life of a single $\mathrm{LiFePO}_{4}$ battery is more than 2000 cycles, but in series, cycle life of $\mathrm{LiFePO}_{4}$ battery pack is far lower than 2000 cycles.

Production processes, initial charge state, cooling conditions and environmental factors will lead to an increase of the battery dispersion and self-discharge rate. Therefore, the capacity differences between batteries will increase [6-9]. Influences of charge cut-off voltage and temperature on performance of lithium ion batteries were studied by Wu Yun et al. [10]. The results show that the higher charge cut-off voltage is, the shorter the battery cycle life is; the higher the temperature is, the faster the fade of single-cell capacity is $[11,12]$.

In this work, over-charge and over-discharge experiments of $\mathrm{LiFePO}_{4}$ battery packs were performed on an experimental platform. Restoration experiments with power batteries were also completed and studied in overdischarge cases. Based on theory and experiments, a battery pack management method for reducing battery damage is proposed.

\section{Experimental}

In the experiments, a 200-Ah $\mathrm{LiFePO}_{4}$ battery pack was provided by a commercial vendor. Sixteen batteries were connected in series. The rated voltage of a $\mathrm{LiFePO}_{4}$ battery is $3.2 \mathrm{~V}$. At room temperature, battery packs were discharged through a three-phase asynchronous motor and charged through the charger. Charge and discharge parameters of $\mathrm{LiFePO}_{4}$ battery packs were set manually. A single battery detection module detected voltage, temperature and other parameters of the single battery. Parameters of the single battery were uploaded to a touch screen microprocessor by CAN communication. The touch screen microprocessor is the heart of battery management system (BMS). The battery pack and the BMS are shown in Figure 1.

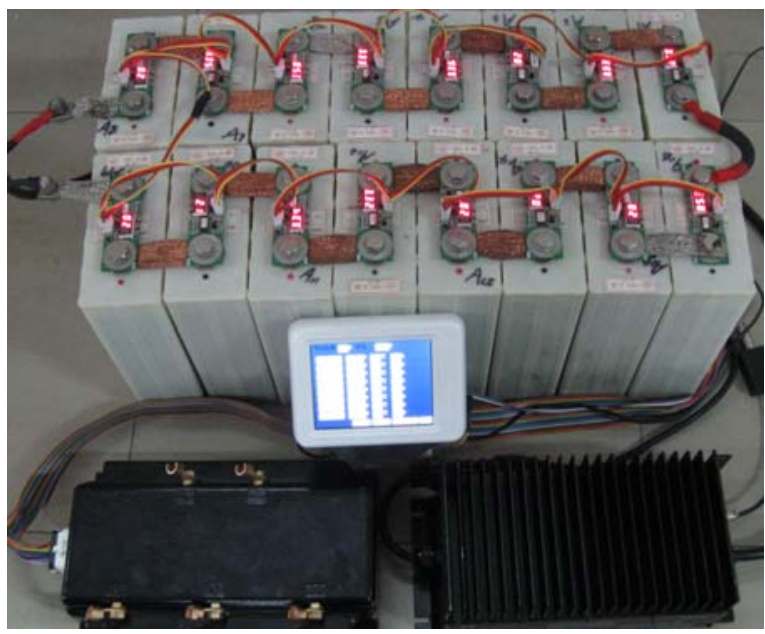

Figure 1. The photo of the battery pack and BMS.

\section{Results and discussion}

\subsection{Over-Charge Characteristic Analysis of Battery Pack}

To study over-charge characteristics of $\mathrm{LiFePO}_{4}$ batteries in cycle charge process, cycle over-charge experiments were carried out on the experimental platform. Figure 2 shows the results of the first cycle over-charge experiment, and Figure 3 shows the results of the tenth cycle over-charge experiment.

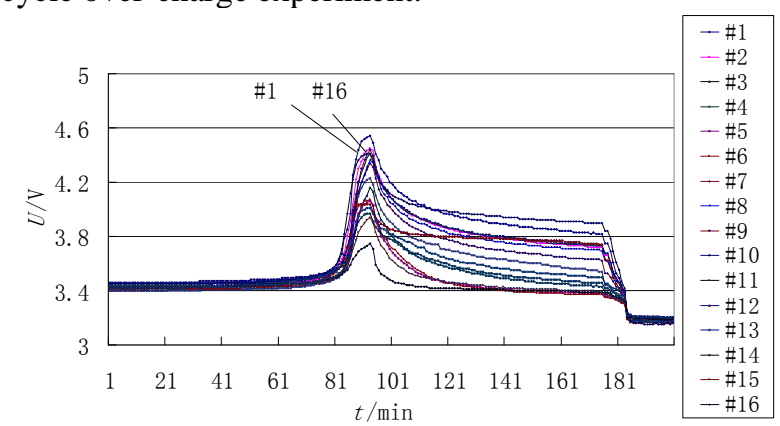

Figure 2. Cycle first over-charge curves of the battery pack. 


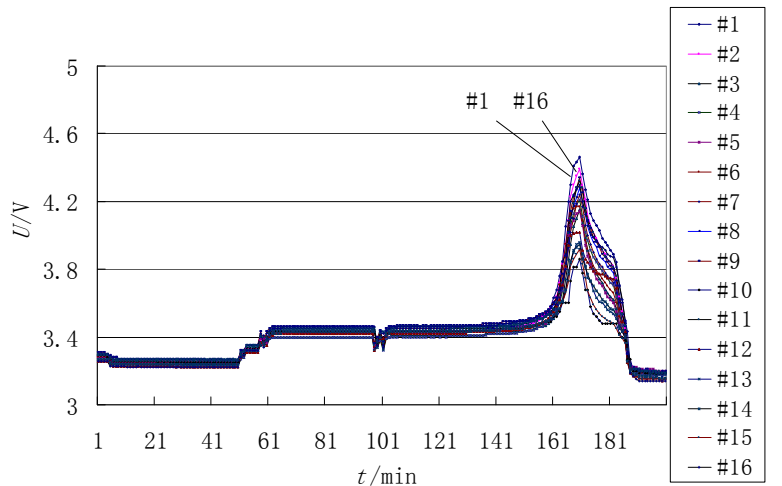

Figure 3. Cycle tenth over-charge curves of the battery pack.

Figure 2 shows that battery pack was charged at a current of 25 A from 1 minute to 86 minutes. In initial charge phase, voltages of the batteries increased slowly, which indicated that the battery has a good chargevoltage plateau. In the late charge phase, the voltages of the batteries increased rapidly, which indicated that the battery had charged almost capacity. The rise rate of the battery voltage began to decline because of the decline of charge current from 87 minutes to 93 minutes. After 94 minutes, voltages of the batteries declined slowly, although charge current dropped to 0 A. The batteries' voltages decreased rapidly when the battery pack was discharged at 174 minutes. The voltage curves in Figure 3 are similar to the voltage curves in Figure 2.

Figure 2 and Figure 3 show that all of batteries were charged at the same time by increasing charge cut-off voltage in the series charge process. Namely, if a particular battery in battery pack is the first one to reach cut-off voltage, it will always be the first one to reach cut-off voltage in the consecutive cycles. For example, see battery \#1 and battery \#16 in Figure 2 and Figure 3. Thus, the battery cannot achieve an equalizing charge by over-charge method. However, the battery pack can be charged to a greater capacity by over-charge method.

Electrochemical reaction equations show that the charge-discharge reaction is completed between $\mathrm{LiFePO}_{4}$ and FePO4 in two phases [13]. During the charging process when lithium ion migrates from $\mathrm{LiFePO}_{4}$ and FePO4 is formed, electrical energy converts into chemical energy. In the series charging process, each cell shifts the same number of lithium ions between the positive and negative, so each cell absorbs the same amount of energy. In the discharging process, lithium ions migrate to FePO4 and forms $\mathrm{LiFePO}_{4}$, and chemical energy converts into electrical energy. Similarly, each cell releases the same amount of energy.

Therefore, to avoid capacity reduction of the battery, $\mathrm{LiFePO}_{4}$ power batteries should avoid over-charge during the charge process, and the charge process should be managed by the BMS.

\subsection{Over-Discharge Characteristic Analysis of Battery Pack}

A large number of charge and discharge experiments were completed before the battery pack was damaged. One charge experiment is shown in Figure 4 and Figure5.
Figure 4 is a voltage curve of each individual cell, and Figure 5 is the total voltage and current curve of the battery pack. The battery pack was charged at a current of $25 \mathrm{~A}$, and the charge cut-off voltage was set to $4 \mathrm{~V}$.

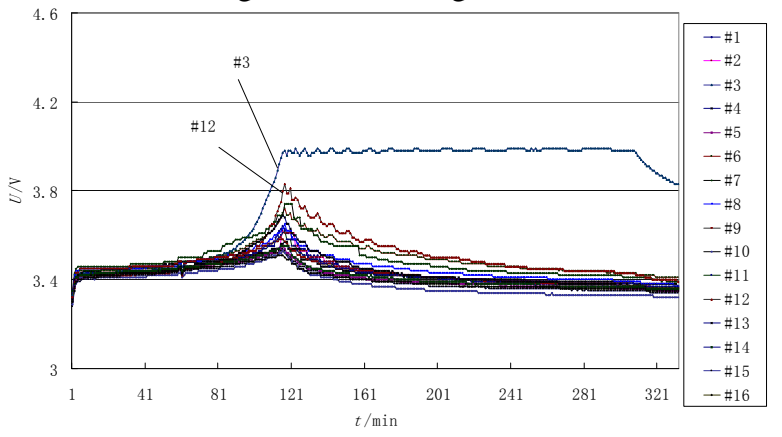

Figure 4. Voltage curve of each individual cell.

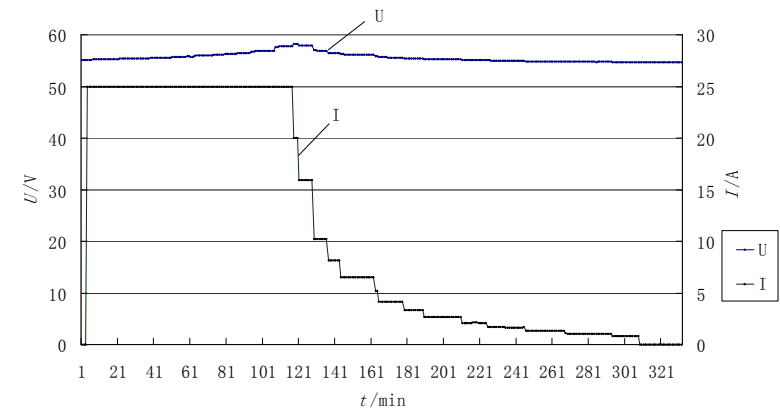

Figure 5. Total voltage and current curve of the battery pack.

Figure 4 and Figure 5 shows that the battery voltage raised rapidly when charging started because of battery polarization. The battery pack was charged at a current of 25 A from 5 minutes to 117 minutes, and the charge current began to decline from 118 minutes to 309 minutes, so the battery voltage did not exceed charge cut-off voltage.

As shown in Figure 4 and Figure5, the voltage of the other 15 cells had a rapid rising trend when the voltage of battery \#3 reached the charge cut-off voltage at 117 minutes. All battery voltages are shown in Table 1 . The voltage increase rate for battery $\# 12$ reached $0.017 \mathrm{~V}$ $(\mathrm{min})^{-1}$, and the voltage increase rate for battery \#16 reached $0.0025 \mathrm{~V}(\mathrm{~min})^{-1}$. From the previous charge analysis of the battery pack, we can see that the 16 cells are essentially fully charged.

Table 1. All battery voltages at 117 minutes.

\begin{tabular}{|c|c|c|c|}
\hline Battery & voltage/V & Battery & voltage/V \\
\hline$\# 1$ & 3.64 & $\# 9$ & 3.58 \\
\hline$\# 2$ & 3.62 & $\# 10$ & 3.53 \\
\hline$\# 3$ & 3.97 & $\# 11$ & 3.61 \\
\hline$\# 4$ & 3.56 & $\# 12$ & 3.80 \\
\hline$\# 5$ & 3.55 & $\# 13$ & 3.69 \\
\hline$\# 6$ & 3.70 & $\# 14$ & 3.55 \\
\hline$\# 7$ & 3.69 & $\# 15$ & 3.54 \\
\hline$\# 8$ & 3.63 & $\# 16$ & 3.51 \\
\hline
\end{tabular}


An over-discharge experiment with the 200 Ah $\mathrm{LiFePO}_{4}$ power battery pack was performed by a threephase asynchronous motor load on the experimental platform. Batteries \#10 through \#13 were damaged (the battery terminal voltage was $0 \mathrm{~V}$ ), the terminal voltage of batteries \#14 and \#15 was approximately $2.71 \mathrm{~V}$, and the other battery voltages were between $3.08 \mathrm{~V}$ to $3.26 \mathrm{~V}$. All battery voltages are shown in Table 2.

Table 2. All battery voltages after over-discharge.

\begin{tabular}{|c|c|c|c|}
\hline Battery & voltage/V & Battery & voltage/V \\
\hline$\# 1$ & 3.20 & $\# 9$ & 3.23 \\
\hline$\# 2$ & 3.21 & $\# 10$ & 0 \\
\hline$\# 3$ & 3.23 & $\# 11$ & 0 \\
\hline$\# 4$ & 3.21 & $\# 12$ & 0 \\
\hline$\# 5$ & 3.21 & $\# 13$ & 0 \\
\hline$\# 6$ & 3.21 & $\# 14$ & 2.71 \\
\hline$\# 7$ & 3.26 & $\# 15$ & 2.71 \\
\hline$\# 8$ & 3.24 & $\# 16$ & 3.08 \\
\hline
\end{tabular}

We can see from Table 2, after battery pack overdischarge, the voltages of batteries \#1 through \#9 are approximately $3.2 \mathrm{~V}$, while the voltages of batteries \#14 and \#15 are only $2.71 \mathrm{~V}$. The voltages for batteries \#10 \#13 have already declined to $0 \mathrm{~V}$. However, the temperatures of batteries did not exceed $60{ }^{\circ} \mathrm{C}$. The batteries bulged slightly but did not ignite or explode. This result shows that $\mathrm{LiFePO}_{4}$ batteries have better safety performance compared with other battery types.

Studies have shown that there are many reasons why the capacity difference increases between the batteries. For example, for the battery production process, the initial charge state is inconsistent with different cooling conditions. Therefore, the battery over-discharge will cause an irreversible reaction. In particular, the battery sustains more severe damage as a result of greater overdischarge.

\subsection{Experimental Analysis of Battery Restoration}

To study the extent of battery damage under overdischarge use, battery restoration experiments were performed on the experimental platform.

All batteries were divided into three categories: batteries \#1 through \#9 and \#16 were in the first pack, batteries \#14 and \#15 were in the second pack, and batteries \#10 through \#13 were in the third pack.

\subsubsection{Restoration experiments for the first pack of batteries}

Because the voltages of the first pack batteries were relatively high, the first pack of batteries was charged at a current of $25 \mathrm{~A}$. The constant current charging time was approximately 8 hours when a single battery voltage reached the $3.65 \mathrm{~V}$ charge cut-off voltage. The actual battery capacity was near the rated capacity. At this point, all battery voltages exceeded $3.50 \mathrm{~V}$ except battery \#16. All battery voltages are shown in Table 3 .

Table 3. All battery voltages at the end charge.

\begin{tabular}{|c|c|c|c|}
\hline Battery & voltage/V & Battery & voltage/V \\
\hline$\# 1$ & 3.61 & $\# 6$ & 3.58 \\
\hline$\# 2$ & 3.61 & $\# 7$ & 3.53 \\
\hline$\# 3$ & 3.65 & $\# 8$ & 3.57 \\
\hline$\# 4$ & 3.53 & $\# 9$ & 3.57 \\
\hline$\# 5$ & 3.54 & $\# 16$ & 3.49 \\
\hline
\end{tabular}

\subsubsection{Restoration experiments for the second pack of batteries}

Because the voltages of the second pack batteries were relatively low, the second pack of batteries was charged at a current of $10 \mathrm{~A}$. The constant current charging time was approximately 19 hours when a single battery voltage reached the $3.65 \mathrm{~V}$. At this point, the voltage of the other battery reached $3.53 \mathrm{~V}$. From the charge process, we can see that the battery is essentially fully charged.

\subsubsection{Restoration experiments for the third pack of batteries}

The voltages of the third pack batteries were $0 \mathrm{~V}$, and the batteries bulged slightly. The third pack of batteries was charged at a current of $5 \mathrm{~A}$. However, battery voltage remained at $0 \mathrm{~V}$. After half an hour, the battery voltage was still $0 \mathrm{~V}$. The anode and the cathode of the battery may have formed a short circuit, and the battery could not absorb energy. After 3 months, the battery voltage was still $0 \mathrm{~V}$. When the battery was charged at a small current, the battery still could not absorb energy. As observed from above analysis, the battery was completely damaged, and the bulge was more pronounced.

Table 3 shows that the first pack of batteries charging capacity is approximately $200 \mathrm{Ah}$, so the batteries are not damaged. The second pack batteries charging capacity is approximately $190 \mathrm{Ah}$, which indicates there is no battery damage. However, the battery's capacity decreased approximately 10 Ah. Supplementary charging experiments for batteries \#10 through \#13 can be observed. The four batteries are already damaged and can no longer charge to capacity. This result may be because long time over-discharge renders the battery unable to restore its capacity.

\subsection{Battery Management System Discussion}

Through experimental analysis of batteries, we draw the conclusion that $\mathrm{LiFePO}_{4}$ battery has a long cycle life, good safety attributes, a high theoretical capacity, low environmental impact and other characteristics; however, it also has many shortcomings, such as need to prevent over-charge, over-discharge, and over-temperature. Otherwise, utilizable capacity of the battery will decrease rapidly, and cycle life will reduce quickly. On this basis, a battery pack management method for reducing power 
battery damage is proposed. Namely, by detecting voltage, temperature and other parameters of each cell, charge and discharge processes of battery pack are monitored and controlled. This management method can avoid battery pack damage problems due to over-charge, over-discharge and over-temperature, and slow the rate of battery pack capacity attenuation and extend the cycle life of battery pack. At the same time, this method can also eliminate or alleviate the impact of completely dead cells in a battery series. The BMS block diagram is shown in Figure 6.

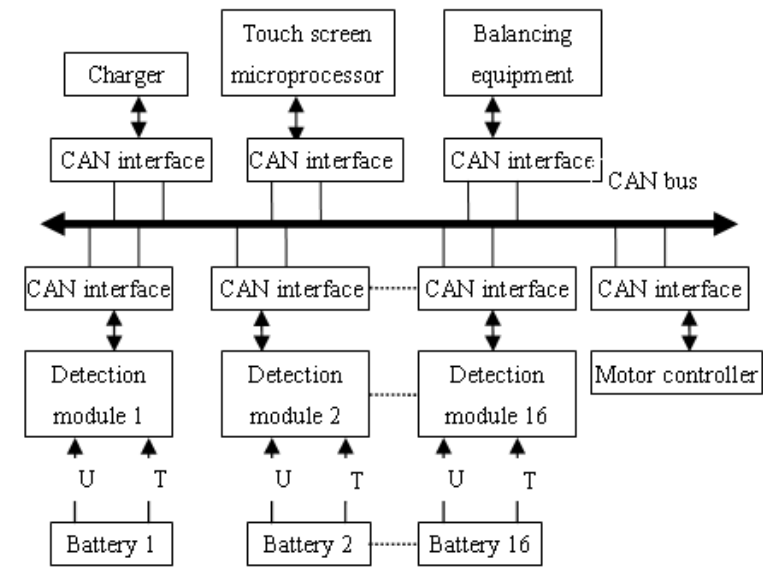

Figure 6. Block diagram of the BMS.

Figure 6 shows that the BMS consists of single celldetection module, CAN communication, touch screen module, charger, equalizing charge equipment and other components. The main BMS functions include series charge-discharge management, equalization charging management and SOC estimation. The voltage and the temperature of each cell have been monitored by the BMS. Series charge, series discharge, equalization charging and SOC are controlled and estimated by the BMS through the analysis of test data. The BMS aptly manages battery pack and avoids battery damages due to over-charge, over-discharge, over-temperature and other reasons. Compared with similar BMS, the BMS in this work has a lower power, lower cost and higher performance characteristics although every single cell is individually monitored.

In addition, the SOC of single batteries and battery pack is estimated by the BMS. The operation mode of the three-phase asynchronous motor is adjusted, and the run distance of EV is estimated by the SOC of battery pack. The state of health of the batteries is evaluated by the BMS.

\section{Conclusions}

In this paper, cycle over-charge and over-discharge experiments of battery pack were performed on the experimental platform at room temperature. Restoration experiments of the batteries were performed and studied under conditions of over-discharge. The results show that over-charge has little impact on the utilizable capacity and dispersion of power batteries in the short term. The batteries can be charged to greater capacity, but the over- charge has a huge impact on cycle life of the battery. The over-discharge has a huge impact on the utilizable capacity and cycle life of the batteries. In particular, overdischarge may completely damage the battery when the battery voltage drops to $0 \mathrm{~V}$, but the battery does not ignite, explode or smoke.

Through the analysis and research of charge and discharge experiments of battery pack, a battery management method of reducing $\mathrm{LiFePO}_{4}$ batteries damage is proposed. Namely, through detecting the voltage, temperature and other parameters of each cell, charge and discharge processes of battery pack are monitored and controlled to prevent battery damage, slow the rate of battery capacity fading, extend cycle life of the battery, and eliminate or alleviate the impact of completely dead cells in a battery series.

\section{Acknowledgement}

Project Supported by Scientific and Technological Research Program of Chongqing Municipal Education Commission (Grant No.KJ1503311).

\section{References}

[1] M. A. Roscher, J. Vetter, D. U.Sauer, J. Power Sources. 191(2009)

[2] M. S. Song, Y. M. Kang, J. H. Kim, H. S. Kim, D. Y. Kim, H. S. Kwon, J. Y. Lee, J. Power Sources. 166(2007)

[3] H. C. Shin, S. B. Park, H. Jang, K. Y. Chung, W. I. Cho, C. S. Kim, B. W. Cho, Electrochim Acta. 53(2008)

[4] C. S. Sun, Z. Zhou, Z. G. Xu, D. G. Wang, J. P. Wei, X. K. Bian, J. Yan, J. Power Sources. 193 (2009)

[5] B. Y. Liaw, M. Dubarry, J. Power Sources. 174(2007)

[6] N. Dupre, J. F. Martin, J. Degryse, V. Fernandez, P. Soudan, D. Guyomard, J. Power Sources. 195(2010)

[7] S. P. Ong, A. Jain, G. Hautier, B. Kang, G. Ceder, Electrochem Communications. 12(2010)

[8] H. Matsui, T. Nakamura, Y. Kobayashi, M. Tabuchi, Y. Yamada, J. Power Sources. 195(2010)

[9] M. Dubarry, B. Y. Liaw, J. Power Sources. 194(2009)

[10]Y. Wu, X. H. Jiang, J. Y. Xie, Chinese Battery Bimonthly. 39 (2009)

[11]M. Dubarry, V. Svoboda, R. Hwu, B. Y. Liaw, J. Power Sources. 174(2007)

[12]K. Amine, J. Liu, I. Belharouak, Electrochemistry Communications. 7(2005)

[13]F. Gao, Z. Y. Tang, Electrochimica Acta. 53(2008) 